are to be released to the wild, severe tooth wear could reduce their life expectancies; therefore, wire mesh containers should be avoided.

Acknowledgements: I thank R. O. Wallace for providing access to the bat colony. For assistance in catching and maintaining the bats, I thank J. A. Dowdy, G. G. Chasko, and P. H. Brockdorff. Finally, I thank E. Dustman for his critical review of the manuscript.

\title{
REFERENCES
}

B a a g $ø$ e H. J., 1977: Age determination of bats (Chiroptera). Vidensk Meddr dansk naturh. Foren., 140: 53-92. Clark D. R., Jr., 1976: Canine tooth wear in captive big brown bats (Eptesicus fuscus). J. Mammal., 57: 778-780.

Accepted, February 20, 1980.

\section{The Effect of $\mid$ Litter Size on Body Weight of Young Rats}

\author{
WPŁYW WIELKOSCI MIOTU NA CIEZAR CIAŁA MŁODYCH SZCZUROW
}

\section{Ewa T. MYSTKOWSKA ${ }^{1}$}

Mystkowska E. T., 1980: The effect of litter size on body weight of young rats. Acta theriol., 25, 21:273-275 [With 1 Table]

A comparison was made of the body weight of embryos 20 days old and newborn rats from litters consisted of $9-10$ young and 13-14 young. Body weight of embryos does not differ significantly and in newborn individuals the difference is significant.

[Inst. Gynaecology \& Obstetrics, Medical Academy, Karowa 2, 00-315 Warszawa].

\section{INTRODUCTION}

It is generally considered that the weight of young mammals depends upon their numbers in the litter, the more numerous the litter, the smaller the weight of the newborn animals ( $\mathrm{G}$ a t e s, 1925; M c L a r e n, 1965). The purpose of the present study was to ascertain at which stage of intrauterine growth such differentiation in weight takes place. To explain this question body weight of 20 day-old embryos and newborn animals from smaller litters (9-10 young per litter) and larger litters (13-14 young per litter) were compared.

\section{MATERIALS AND METHODS}

The material consisted of 199 20-day old ambryos and placentae, and 204 newborn young of the Wistar random bred rats. Female - mothers were fed on the standard granulated feed and supplied with tapwater. The period of light was controlled - 14 hours light per 24 hours. As from the 20 th day of gestation females about to bear young were kept singly in separate cages.

The embryos were removed from the uterus on the 20th day of gestation between $10^{00}$ and $13^{\text {ro }}$. The first day of preonancy was taken the day in which spermatozoa in vaginal smear were found. The embryos were removed from the foetal membranes, separated from the umbilical cord and the embryos and placentae weighed.

1 Present address: Inst. Biostructure, Medical Academy, Chałubińskiego 5, 02-004 Warszawa. 
Newborn animals were weighed on the day of birth between $10^{\circ 0}$ and $13^{\text {co }}$. Average duration of gestation $\overline{\mathrm{x}} \pm$ S.D. $=22.1 \pm 0.40$ days. Only those embryos and newborn individuals originating from litters numbering $9-10$ and $13-14$ were taken for the studies.

Significance of differences between mean values was checked by means of the $t$ Student test.

\section{RESULTS}

Ranges of variation and mean weights of embryos and placentae in less numerous (9-10) and more numerous (13-14) litters are given in the table. On average, the weight of embryos from less and more numerous litters does not differ significantly, neither does the weight of the placenta in these two groups. On the other hand the body weights of newborn individuals from smaller litters differ to a highly

Table 1

Comparison of the weight $(\mathrm{mg})$ of embryos and placentae and weight (mg) of newborn Wistar rats from litters of $9-10$ and $13-14$ young.

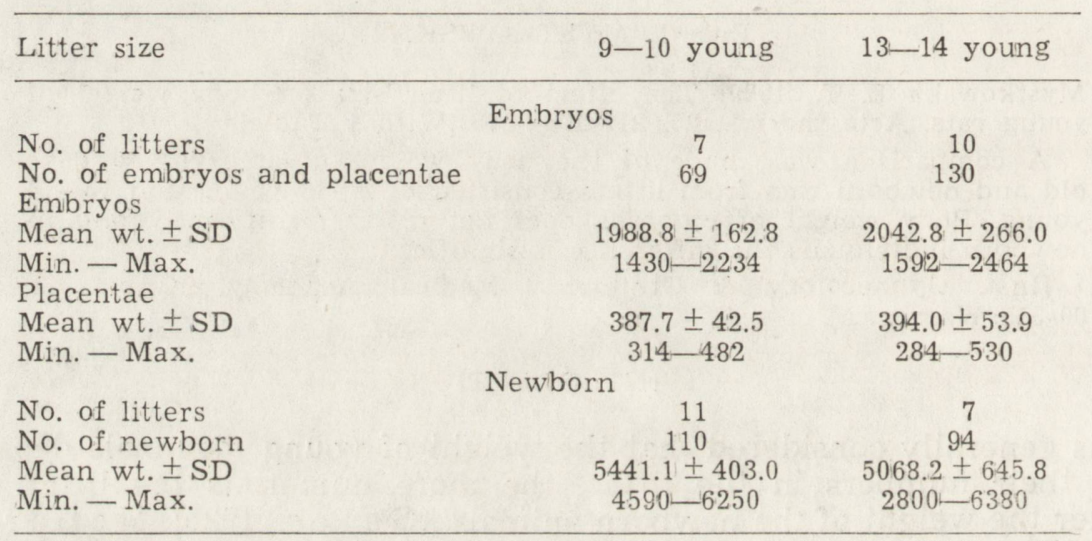

significant degree from the weight of newborn individuals from larger litters. Value $t=4.880, p=0.001, \mathrm{~N}=202$.

\section{DISCUSSION}

The results presented here indicate that differences in the weight of young rats, depending on litter-size, described by a large number of authors ( $\mathrm{G}$ a te s, 1925; M c L a r e n, 1965), arise during the final period of gestation prior to birth. The development of the embryo between the 20th day and birth (22nd day) is distinguished by a sudden increase in mass: an increase of about $170 \%$ in two days. According to the haemodynamic theory of $\mathrm{Healy}$ et al. (1960) and $\mathrm{McL}$ a re $\mathrm{n}$ \& M ic hie (1960b), the amount of nutritive substances available for the embryo's growth depends both on the mother's blood pressure at which blood reaches the placenta, and on the size of the placenta, and in turn the size of placenta depends on the mother's blood pressure. 
The greater is the number of placentae, the lower is the mother's blood pressure, while the lower the blood pressure, the poorer the embryo's nutrition. In the light of this theory it would appear obvious that during the time of rapid increase in the embryo's mass the amount of nutritive substances supplied to the embryo from mother's blood is of prime importance. The larger the number of embryos the smaller the increase in their body weight. In addition, according to $\mathrm{M} c \mathrm{~L}$ a $\mathrm{r}$ e n (1965), a mechanical factor may also effect the size of embryos: the more embryos there are in the uterine horn, the greater the mechanical pressure exerted by its walls on the embryos. This factor may also act more effectively at the time of intensive increase in the embryo's mass.

M c La ren (1965), in examining the body weight of 17.5-day old mice embryos, found a slight difference in weight between less and more numerous litters. These studies were, however, made 24 hours before birth, and the difference for one line of mice examined was not statistically significant. A highly significant difference in the weight of young mice depending on their number in a litter did not occur until the time of birth, and therefore these data agree with the observations presented here.

It seems acceptable that difference in body weight depending on iitter size occurs only in the last few days of intensive body growth before birth.

Acknowledgements: I should like to express my gratitude to all the members of the Laboratory of Experimental Embryology of the Institute of Obstetrics and Gynaecology of the Medical Academy for their assistance in collecting the material.

\section{REFERENCES}

G a tes W. H., 1925: Litter size, birth weight and early growth rate of mice (Mus musculus). Anat. Rec., 29: 183-193. H e a ly M., M c Laren A. \& M i c hi e D., 1960: Foetal growth in the mouse. Proc. roy. Soc., B, 153: $367-379$. M c La r e n A., 1965: Genetic and environmental effects on foetal and placental growth in mice. J. Reprod. Fertil. 9: 79 98. M c L a ren A. \& M i c hi e D. 1960b: Control of prenatal growth in mammals. Nature, Lond., 187: 363-365.

Accepted, February 29, 1980. 